\title{
A study on relationship between female employees' organizational citizenship behavior and job satisfaction within organization
}

\author{
Majid Iranshahi $^{\mathbf{a}^{*}}$, Morteza Ghasemi ${ }^{\mathrm{b}}$ and Ali Noori Motlagh
}

${ }^{a}$ M.A. in Public Administration, Management Department, Islamic Azad University, Arak Branch, Arak, Iran

${ }^{b}$ Member of Management Department, Islamic Azad University, Arak Branch, Arak, Iran

\begin{tabular}{l}
\hline C H R O N I C L E \\
\hline Article history: \\
Received May 25, 2013 \\
Received in revised format \\
28 June 2013 \\
Accepted 2 August 2013 \\
Available online \\
August 102013 \\
\hline Keywords: \\
Female Employees \\
Organizational Satisfaction \\
OCB \\
\end{tabular}
A B S T R A C T

\begin{abstract}
This paper presents an investigation to assess the relationship between female employees' organizational citizenship behavior and job satisfaction within organization. A questionnaire is designed and distributed among employees who work in city of Qom, Iran and after analyzing the responses by SPSS software program, the relationships between variables are assessed by Pearson test after confirming the normality of the data using Kolmogrov-Smirnov test. The results of the studies reflect a strong relationship between citizen-organization behavior of female employees and job satisfaction. In addition, the survey examines six sub-hypotheses and confirms that there are positive and meaningful relationships between female employees' custom, altruism, work consciousness, mutual coordination, fairness and courtesy on one side and job satisfaction on the other side.
\end{abstract}

\section{Introduction}

During the past few years, there have been different studies on learning more about women's job satisfaction and organizational citizenship behavior (Mirabizadeh \& Gheitasi, 2012). Heidarzadeh Hanzaee and Mirvaisi (2013), for instance, performed a survey on effect of emotional intelligence, organizational citizenship behaviors and job satisfaction on employees' performance in Iranian hotel industry. The objective of the study was to study the impact of employees' Emotional Intelligence (EI), Job Satisfaction (JS) and Organizational Citizenship Behavior (OCB) on Employee's Performance (EP) in Iranian hotel industry. They designed a questionnaire and distributed it among 225 employees who had a high interaction with customers in hotel industry and using the art of structural equations model (SEM) confirmed all the proposed hypotheses of this survey except the one, which was associated with the relationship between OCB on EP. They concluded that EI had positive impacts on JS, OCB and EP in Iranian hotel industry.

*Corresponding author. Tel:+989111434853

E-mail address: majid.iranshahy@gmail.com (M. Iranshahi) 
Moghaddampour and Karimian (2013) reported a study on impact of workplace spirituality on customer-oriented organizational citizenship behavior by considering the role of spiritual intelligence in a case study of an Iranian insurance company. They reported that spiritual intelligence and workplace spirituality had positive influence on customer-oriented organizational citizenship behavior. However, when spiritual intelligence was considered as a moderating factor, spirituality development in workplace cannot alone impact on customer-oriented organizational citizenship behavior since including spiritual intelligence hedges the impact of workplace spirituality on customer-oriented organizational citizenship behavior though workplace spirituality could improve customer-oriented organizational citizenship behavior through impacting on spiritual intelligence.

Khodaei et al. (2013) performed a study on the effect of social capital on job satisfaction and citizenship behavior among employees of a governmental university in Iran and confirmed that there were some positive and meaningful relationship between social capital and job satisfaction. Iravani et al. (2013) performed a social work study on the effect of gender and marital status on job satisfaction. They reported that there was no difference between female and male employees in terms of job satisfaction and confirmed that marital status had no significance on job satisfaction. Sadati (2012) performed a survey on relationship between organizational culture and organizational citizenship behavior with employees' empowerment.

\section{The proposed study}

In this paper, we study the relationship between female employees' organizational citizenship behavior and job satisfaction within organization. The study is performed on 53 organizations located in 8 locations in city of Qom, Iran with 220 employees. The sample size is calculated as follows,

$n=\frac{N \times z_{\alpha / 2}^{2} \times p \times q}{\varepsilon^{2} \times(N-1)+z_{\alpha / 2}^{2} \times p \times q}$,

where $N$ is the population size, $p=1-q$ represents the yes/no categories, $z_{\alpha / 2}$ is CDF of normal distribution and finally $\varepsilon$ is the error term. Since we have $p=0.5, z_{\alpha / 2}=1.96$ and $N=220$, the number of sample size is calculated as $n=102$. Accordingly, 23 government helpdesks including 102 male and female employees have complotted the questionnaire. A questionnaire is designed and distributed among employees and after analyzing the responses by SPSS software program, the relationship between variables. The study first uses Kolmogrov-Smirnov test and verifies that all data are normally distributed $(\alpha=5 \%)$ and therefore, uses Pearson test to examine different hypotheses. The research question is as follows:

Main hypothesis: There is a relation between organizational citizenship behavior of female employees within organizations and job satisfaction.

To test this hypothesis, we use Pearson correlation test and Table 1 summarizes the results of our survey.

Table 1

The summary of Pearson correlation ratio between organizational citizenship behavior and job satisfaction

\begin{tabular}{|c|c|c|c|}
\hline & & Organizational citizenship behavior & Job satisfaction \\
\hline \multirow{3}{*}{$\begin{array}{l}\text { Organizational citizenship } \\
\text { behavior }\end{array}$} & Pearson Correlation & 1.000 & $.709^{* *}$ \\
\hline & Sig. & . & .000 \\
\hline & $\mathrm{N}$ & 77 & 75 \\
\hline \multirow{3}{*}{ Job satisfaction } & Pearson Correlation & $.709^{* *}$ & 1.000 \\
\hline & Sig. & .000 & . \\
\hline & $\mathrm{N}$ & 75 & 95 \\
\hline
\end{tabular}

**. Correlation is significant at the 0.01 level (2-tailed). 
As we can observe from the results of Table 1, there is a meaningful relationship between organizational citizenship behavior and job satisfaction when the level of significance is one percent. Therefore, the main hypothesis of this survey has been confirmed.

There are six sub-hypotheses associated with the proposed study of this paper, which are examined next.

\subsection{The first sub-hypothesis: The relationship between job satisfaction and women's custom}

The first sub-hypothesis of this survey investigates the relationship between job satisfaction and women's custom, where questions 1-5 of the questionnaire are associated with social customs and questions 29-35 and 43 are associated with job satisfaction. The following states the hypothesis of the survey and the results are summarizes in Table 2.

$\mathrm{H}_{0}$ : There is no relationship between the social customs of the employed women in the organization and job satisfaction.

$\mathrm{H}_{1}$ : There is a relationship between the social customs of the employed women in the organization and job satisfaction.

\section{Table 2}

The summary of testing the relationship between social customs and job satisfaction

\begin{tabular}{cccc}
\hline & & Social customs & Job satisfaction \\
\hline \multirow{3}{*}{ Social customs } & Pearson Correlation & 1.000 & $.609^{* *}$ \\
& Sig. &. & .000 \\
& $\mathrm{~N}$ & 95 & 90 \\
\multirow{3}{*}{ Job satisfaction } & Pearson Correlation & $.609^{* *}$ & 1.000 \\
& Sig. & .000 &. \\
\hline *** Correlation is significant at the 0.01 level (2-tailed) & $\mathrm{N}$ & 90 & 95
\end{tabular}

The results of Table 2 clearly show that there is a positive and meaningful relationship between job satisfaction and women's social customs when the level of significance is one percent. Therefore, we can confirm the first sub-hypothesis of the survey.

\subsection{The second sub-hypothesis: The relationship between altruism and job satisfaction}

The second sub-hypothesis of this survey investigates the relationship between job satisfaction and women's altruism. The following states the hypothesis of the survey and the results are summarizes in Table 3.

$\mathrm{H}_{0}$ : There is no relationship between the employed women's altruism in the organization and job satisfaction.

$\mathrm{H}_{1}$ : There is a relationship between the employed women's altruism in the organization and job satisfaction.

The results of Table 3 clearly show that there is a positive and meaningful relationship between job satisfaction and women's altruism when the level of significance is one percent. Therefore, we can confirm the second sub-hypothesis of the survey. 


\section{Table 3}

The relationship between altruism and job satisfaction

\begin{tabular}{cccc}
\hline & & altruism & job satisfaction \\
\hline \multirow{2}{*}{ altruism } & Pearson Correlation & 1.000 & $.549^{* *}$ \\
& Sig. &. & .000 \\
& $\mathrm{~N}$ & 98 & 91 \\
\hline \multirow{3}{*}{ job satisfaction } & Pearson Correlation & $.549^{* *}$ & 1.000 \\
& Sig. & .000 &. \\
\hline ** Correlation is significant at the 0.01 level (2-tailed) & $\mathrm{N}$ & 91 & 95 \\
\hline
\end{tabular}

\subsection{The third sub-hypothesis: The relationship between work consciousness and job satisfaction}

The third sub-hypothesis of this survey investigates the relationship between job satisfaction and women's work consciousness. The following states the hypothesis of the survey and the results are summarizes in Table 4.

$\mathrm{H}_{0}$ : There is no relationship between the employed women's work consciousness in the organization and job satisfaction.

$\mathrm{H}_{1}$ : There is a relationship between the employed women's work consciousness in the organization and job satisfaction.

\section{Table 4}

The relationship between work consciousness and job satisfaction

\begin{tabular}{cccc}
\hline & & work consciousness & job satisfaction \\
\hline \multirow{2}{*}{ work consciousness } & Pearson Correlation & 1.000 & $.638^{* *}$ \\
& Sig. &. & .000 \\
& $\mathrm{~N}$ & 91 & 86 \\
\hline \multirow{2}{*}{ job satisfaction } & Pearson Correlation & $.638^{* *}$ & 1.000 \\
& Sig. & .000 &. \\
\hline **. Correlation is significant at the 0.01 level (2-tailed). & 86 & 95 \\
\hline
\end{tabular}

The results of Table 4 clearly specify that there is a positive and meaningful relationship between job satisfaction and women's work consciousness when the level of significance is one percent. Therefore, we can confirm the third sub-hypothesis of the survey.

\subsection{The fourth sub-hypothesis: The relationship between mutual coordination and job satisfaction}

The fourth sub-hypothesis of this survey studies the relationship between job satisfaction and women's mutual coordination. The following states the hypothesis of the survey and the results are summarizes in Table 5.

$\mathrm{H}_{0}$ : There is no relationship between the employed women's mutual coordination in the organization and job satisfaction.

$\mathrm{H}_{1}$ : There is a relationship between the employed women's mutual coordination in the organization and job satisfaction. 
Table 5

The relationship between mutual coordination and job satisfaction

\begin{tabular}{cccc}
\hline & & work consciousness & job satisfaction \\
\hline \multirow{3}{*}{ mutual coordination } & Pearson Correlation & 1.000 & $.419^{* *}$ \\
& Sig. &. & .000 \\
& $\mathrm{~N}$ & 92 & 88 \\
\hline \multirow{3}{*}{ job satisfaction } & Pearson Correlation & $.419^{* *}$ & 1.000 \\
& Sig. & .000 &. \\
\hline **. Correlation is significant at the 0.01 level (2-tailed). & 88 & 95 \\
\hline
\end{tabular}

The results of Table 5 clearly specify that there is a positive and meaningful relationship between job satisfaction and women's work consciousness when the level of significance is one percent. Therefore, we can confirm the fourth sub-hypothesis of the survey.

\subsection{The fifth sub-hypothesis: The relationship between fairness and job satisfaction}

The fifth sub-hypothesis of this survey studies the relationship between job satisfaction and women's fairness. The following states the hypothesis of the survey and the results are summarizes in Table 6 .

$\mathrm{H}_{0}$ : There is no relationship between the employed women's fairness in the organization and job satisfaction.

$\mathrm{H}_{1}$ : There is a relationship between the employed women's fairness in the organization and job satisfaction.

\section{Table 6}

The relationship between fairness and job satisfaction

\begin{tabular}{cccc}
\hline & & fairness & job satisfaction \\
\hline \multirow{2}{*}{ fairness } & Pearson Correlation & 1.000 & $.527^{* *}$ \\
& Sig. &. & .000 \\
& $\mathrm{~N}$ & 99 & 94 \\
\hline \multirow{3}{*}{ job satisfaction } & Pearson Correlation & $.527^{* *}$ & 1.000 \\
& Sig. & .000 &. \\
\hline **. Correlation is significant at the 0.01 level (2-tailed). & 94 & 95 \\
\hline
\end{tabular}

The results of Table 6 clearly specify that there is a positive and meaningful relationship between job satisfaction and women's fairness when the level of significance is one percent. Therefore, we can confirm the fifth sub-hypothesis of the survey.

\subsection{The sixth sub-hypothesis: The relationship between courtesy and job satisfaction}

The last sub-hypothesis of this survey studies the relationship between job satisfaction and women's courtesy. The following states the hypothesis of the survey and the results are summarizes in Table 7.

$\mathrm{H}_{0}$ : There is no relationship between the employed women's courtesy in the organization and job satisfaction.

$\mathrm{H}_{1}$ : There is a relationship between the employed women's courtesy in the organization and job satisfaction. 
Table 7

The relationship between courtesy and job satisfaction

\begin{tabular}{cccc}
\hline & & courtesy & job satisfaction \\
\hline \multirow{2}{*}{ courtesy } & Pearson Correlation & 1.000 & $.568^{* *}$ \\
& Sig. &. & .000 \\
& $\mathrm{~N}$ & 96 & 90 \\
\hline \multirow{3}{*}{ job satisfaction } & Pearson Correlation & $.568^{* *}$ & 1.000 \\
& Sig. & .000 &. \\
\hline **. Correlation is significant at the 0.01 level (2-tailed). & 90 & 95 \\
\hline
\end{tabular}

The results of Table 7 clearly specify that there is a positive and meaningful relationship between job satisfaction and women's courtesy when the level of significance is one percent. Therefore, we can confirm the last sub-hypothesis of the survey.

\section{Discussion and conclusion}

In this paper, we have performed an empirical investigation to study the relationship between female's employees' organizational citizenship behavior and job satisfaction. The survey has been conducted among some randomly selected female employees who worked for different organizations in city of Qom, Iran. The survey has used Pearson correlation test to examine the relationship between different components of the survey. The results of testing six sub-hypotheses have confirmed that there were some positive and meaningful relationship between custom (Pearson correlation $=$ 0.609 , P-value $<0.01$ ), altruism (Pearson correlation $=0.549$, P-value $<0.01$ ), work consciousness (Pearson correlation $=0.419, \mathrm{P}$-value $<0.01)$, mutual coordination $($ Pearson correlation $=0.527, \mathrm{P}$ value $<0.01$ ), fairness and courtesy (Pearson correlation $=0.568, \mathrm{P}$-value $<0.01$ ) one side and job satisfaction on the other side. The result of Pearson correlation test between organizational citizenship behavior and women's job satisfaction has already been confirmed (Pearson correlation $=0.709$, Pvalue $<0.01)$.

\section{References}

Heidarzadeh Hanzaee, K., \& Mirvaisi, M. (2013). A survey on impact of emotional intelligence, organizational citizenship behaviors and job satisfaction on employees' performance in Iranian hotel industry. Management Science Letters, 3(5), 1395-1402.

Iravani, M.R., Hosseini, S.S., Rajabi, M., Fakhri Fakhramini, A., Mirhaj, S., \& Shirvani, M. (2013). A social work study on the effect of gender and marital status on job satisfaction. Management Science Letters, 3(8), 2285-2288.

Khodaei, R., Khodaei Valehzaghard, H., \& Anvar, H. (2013). A study on the effect of social capital on job satisfaction and citizenship behaviour. Management Science Letters, 3(7), 1837-1878.

Mirabizadeh, M., \& Gheitasi, S. (2012). Examining the organizational citizenship behavior as the outcome of organizational commitment: Case study of universities in Ilam. Management Science Letters, 2(3), 951-960.

Moghaddampour, J., \& Karimian, M.V. (2013). A study on impact of workplace spirituality on customer-oriented organizational citizenship behavior by considering the role of spiritual intelligence: A case study of an insurance company. Management Science Letters, 3(6), 16331648.

Sadati, S.E. (2012). A survey relation of organizational culture and organizational citizenship behavior with employees' empowerment. Management Science Letters, 2(6), 2175-2186. 